\title{
PERSPECTIVE
}

\section{Longer life and stagnated retirement age: Sri Lankan perspectives}

\author{
W. Savithri M. Goonatilaka ${ }^{1^{*}}$ W. Indralal De Silva ${ }^{2}$ \\ ${ }^{1}$ Department of Geography, University of Kelaniya, Colombo, Sri Lanka \\ ${ }^{2}$ Department of Demography, University of Colombo, Colombo, Sri Lanka
}

\section{Check for updates}

Correspondence to: W. Savithri M. Goonatilaka, Department of Geography, University of Kelaniya, Colombo, Sri Lanka;

E-mail: goonatilaka_savithri@yahoo.com

Received: November 30, 2021

Accepted: January 18, 2022;

Published: January 21, 2022.

Citation: Goonatilaka WSM and De Silva WI. Longer life and stagnated retirement age: Sri Lankan perspectives. Soc Work Soc Welf, 4(1): 179-184. https://doi.org/10.25082/SWSW.2022.01.002

Copyright: (c) 2022 W. Savithri M. Goonatilaka et al. This is an open access article distributed under the terms of the Creative Commons Attribution License, which permits unrestricted use, distribution, and reproduction in any medium, provided the original author and source are credited.

\begin{abstract}
Demographic ageing, resulting from rapidly increasing life expectancy and decreasing birth rate, raises a number of challenges. Many countries in the world are raising the age of retirement eligibility because of the significant rise in life expectancy. Although Sri Lankan demographic environment also demonstrates an increase of life expectancy and ageing, the Government has not made comparable increases in the age of retirement. In this backdrop, this paper using both primary and secondary data, examines the timely debate of increasing the mandatory retirement age of the country. The government officials in Sri Lanka can work up to the age of 60 years without seeking extension and at the age of 60 years retirement is compulsory. Recently the government has proposed to extend the mandatory retirement age of them 63 years. At the same time age relating to contributory schemes such as, farmers' pension and social security pension, have also been extended from 60 to 63 years. The number of government pensioners is increasing significantly, putting more pressure on the recurrent expenditure of the government. Empirical data reveal that the Sri Lankans seems healthier in terms of life expectancy, healthy life expectancy and HDI. Compared to other south Asian countries with similar heath status Sri Lanka enjoys a long retirement period providing the fact that Sri Lankans are capable of working more productive years after retirement age. In fact, as of 2012, male and female retiree at age 60 could survive for another 17 and 21 years respectively. Also increasing the mandatory retirement age will be a partial solution to the anticipated labour shortages in near future arising due to rapid ageing process. However, the rise in longevity is exerting pressure on public finances with increases in pension and elderly care expenses. Hence, it seems timely to consider increasing the mandatory retirement age of the government officials, after assessing the merits and demerits of such measure.
\end{abstract}

Keywords: longer life, retirement, age of retirement, government pension

\section{Introduction}

Population aging has been the subject of much discussion during the past few years in Sri Lanka. However, the retirement is referred to the point where a person stops his employment completely for the working life. In this context it is clear that the retirement links with ageing. On the other hand, increasing the retirement age of a particular community must be fit enough to work a few more years after its member's existing retirement age. Sri Lankan work force comprises with four categories - the government sector, semi-government sector, private sector, and informal and self-employed sector. However, informal and self-employed sector retirement age seems to depend on personal decisions. But most of the informal and self-employed sector people continue their work long time in their old ages. However, their working life terminate due to health reasons but other sectors retirement age deal with rules and regulation issued by the government ordinance and legislation in Sri Lanka.

Demographic patterns in Sri Lanka are also exerting pressure on governments to spend more on pensions. The fluctuations and uncertainty in life expectancy are disrupting the forecasts on pension schemes. For example, every year of increased life expectancy could increase pension plan liabilities by three to four percent. According to the Department of Census and Statistics in year 2018, out of 8.0 million workers, 14.5 percent belonged to the government sector while 43.3 percent were employed in the private sector and 32.3 percent of workers were own account workers. Another 7.2 percent belongs to unpaid family workers while remaining 2.8 percent was employers. Compared with previous data, it is observed that the structure of the employment in Sri Lanka is changing. Considering the other South Asian countries, formal sector has retired its workers at age 60 or above maximum 65 years. According to the World Bank (2008) [1] the unprotected informal and self-employed sector has no retirement age in Sri 
Lanka. The demographic transition and resultant changes in the labour force are both challenges in employment similar to many other countries in the world. Like that in line with demographic transition of the Sri Lankan population the potential labour force is expected to shrink in to the coming decade.

In this backdrop, this paper using both primary and secondary data, examines the timely debate of increasing the mandatory retirement age of the country. Primary data was collected through 12 key informant interviews which were conducted in the latter part of year 2019. Secondary data was obtained from various government institutes, including the Department of Pension, Sri Lanka Social Security Board and Agriculture and agrarian Insurance Board in Sri Lanka.

\section{Need for increasing the mandatory retirement age in Sri Lanka}

Before explaining the need for increasing the mandatory retirement age in the country, it is needed to understand the mandatory retirement age in Sri Lanka. According to the Ordinance No.11 of 1910 [2] which is known as the public and judicial officers' retirement ordinance was enacted to provide compulsory retirement age for public and government officials. However the compulsory retirement age was set as years 57 by the act and currently it has been amended as years 60. In addition, the ordinance makes retirement below 55 as unlawful unless it is objectively justified. According to the ordinance and legislations an employee has an option to request to work beyond 55 years. If it is further mention that if an employer considering the good health, specialist knowledge and skills of the employee may provide extension of the working life. The current practice is that the state officials can extends of her or his service until 57 years retirement. This situation was further changed and currently government officials have opportunity to work until 60 years without extension of the service and some specific categories of employment has opportunity to work beyond that age. Not only ordinance No 11 of 1910 [2] but also some other enactments specify retirement age for government employees. One example is the 1978 constitution of Sri Lanka [3]. According to the Article 107 of constitution sets the age at 65 as retirement age for supreme court judges of Sri Lanka and 63 years for judges of the court of appeal. Furthermore, the section 6(3) of judicature Act, No. 2 of 1978 provides legislation for high court judges to retire at the age 61. It is notable fact here is that ordinance No 11 of 1910 [2] was enacted in a period when life expectancy at the age 60 of the country was around 11 years. Table 1, shows that the life expectancy and retirement age in selected countries in the world including Sri Lanka.

Table 1 Life expectancy and retirement age in selected countries

\begin{tabular}{lccc}
\hline Country & Life expectancy at age 60 & Retirement age & Time period of pension payment \\
\hline Sri Lanka & 21 & $55^{*}$ & $21-26$ \\
India & 18 & 60 & 18 \\
Bangladesh & 19 & 59 & 20 \\
Pakistan & 18 & 60 & 18 \\
China & 20 & 60 & 20 \\
Singapore & 25 & 67 & 18 \\
United Kingdom & 24 & 65 & 19 \\
\hline
\end{tabular}

Note: * At present government officials mandatory retirement age stand at 60 years. Source: United Nations, 2018 [4].

Globally, the increase in elderly populations and rising life expectancy have exploded policy level discussions to identify sustainable solutions to tackle the growing financial stress on social security systems. On the other hand, global access to healthcare facilities improves and becomes more reasonable in low-income countries, life expectancy might increase even further. While this will be largely seen as the success of neo-liberal economic policies and social welfare schemes, it is likely to bring forth a unique set of challenges for governments.

Elderly population will grow more dependent on the state for pension pay-outs to meet their post-retirement living expenses. On the other hand, we have already seen such trends in countries where elders constitute a significant percentage of the total population. Sri Lanka, for example, spent roughly Rs 19.5 billion (1 US \$ = Rs. 200) for 651,120 pensioners as a pension payment in 2020, which was one of the large expenditures in the fiscal year (Department of Pension, 2020) [5]. However, improvements in life expectancy accelerate the funding requirements of pension plans. For example, if a retiree lives one extra year in retirement, governments will have to find additional resources to pay the pension and other related benefits. This, with the 
increasingly growing senior population, will put more pressure on government revenues and leave many seniors deprived of their pension benefits.

Considering Sri Lanka, it has shown the fastest ageing population in the South Asian Region. According to the De Silva \& De Silva (2015) [6] The elderly proportion of 6.6 percent of the total population in 1981 increased to 12.4 percent by 2012. Between 1981 and 2012 the volume of the elderly increased more than doble from 1.0 million to 2.5 million and is expected to increase to 5.2 million by 2037 which would increase during the immediate 20 -year period. In term of the proportion of elderly relatively to the total population a strong liner increases visible. Compared to the other south Asian countries' population belonging to the age group 60 years and above is significantly higher in Sri Lanka. The reasons behind that this could the massive decline in fertility and increase in the life expectancy.

According to De Silva (2008) [7] Life expectancy in Sri Lanka during the period of 19621964 elucidated that female life expectancy surpassed that of male by 0.4 years (Table 2). Since then, the life expectancy for both sexes increased considerably. But more favor of females During the 1980-1982 the life expectancy for male and females reached 67.7 and 72.1 years respectively. These figures reveal that females have consistently longer life expectancy than males in Sri Lanka. However, for the period of 2000-2002 male life expectancy at birth in Sri Lanka was estimated to be 68.1 years. While the corresponding estimate for females was 76.6 years. As of the latest life table of 2011-2013, the life expectancy at birth of males and females increased to 72.0 and 78.6 years respectively. Although the gender gap in life expectancy in 2000-2002 was 7.5 years, in the latest period it has declined to 6.6 years (Table 2).

Table 2 The life expectancy at birth and at age 60 years, Sri Lanka

\begin{tabular}{cccccc}
\hline \multirow{2}{*}{ Year } & \multicolumn{2}{c}{ At Birth } & & \multicolumn{2}{c}{ At age 60 } \\
\cline { 2 - 3 } \cline { 5 - 6 } & Male & Female & & Male & Female \\
\hline $1900-1902$ & 36.4 & 34.2 & & 11.5 & 10.6 \\
$1920-1922$ & 32.7 & 30.7 & & 14.5 & 14.5 \\
$1945-1947$ & 46.8 & 44.7 & & 16.0 & 14.9 \\
1953 & 58.8 & 57.5 & & 16.6 & 17.0 \\
$1962-1964$ & 63.3 & 63.7 & & 16.6 & 17.8 \\
$1970-1972$ & 64.0 & 66.9 & & 18.0 & 20.0 \\
$1980-1982$ & 67.7 & 72.1 & & 17.2 & 21.3 \\
$2000-2002$ & 68.1 & 76.6 & & 17.2 & 21.3 \\
$2011-2013$ & 72.0 & 78.6 & 17.5 & 21.8 \\
\hline
\end{tabular}

Source: De Silva, 2008 [7]; De Silva \& De Silva, 2015 [6].

The life expectancy figures for 20112013 demonstrated a further increase in survival at age 60 years 17.5 and 21.8 years for males and females respectively (last two columns of Table 2). Therefore, the elderly in the total population of Sri Lanka is also increasingly becoming disproportionately female. All these demographic changes have highlighted the issues of an ageing population, particularly the long years of survival of Sri Lankans after 60 years in the coming decades (De Silva, 2015).

The nature of the changes that occurred in the Sri Lankan's population pyramid depict the manner in which the age sex structure of Sri Lankan's population has changed. According to the De Silva (2015) the proportion of people in various age and sex categories change because of continuous action of population growth components, namely mortality fertility and migration. The nature of changes happened in Sri Lankan's population pyramid is depicted in Figure 1. The following population pyramid constructed for year 2012 and 2022 demonstrate significant changes occurring in Sri Lanka. It is noted that along with the age structure transition from 2012 to 2022 the working age population (age 15-59) has significantly increase. This enhancement in the labour force will continue for a few more decades until it reaches a situation where the age 60 and above population starts growing.

\section{Retirement age and the health status of Sri Lankans}

Though we are living longer, this doesn't necessarily mean our health will allow us to work for additional years. Healthy working life expectancy tells us the average number of years people in a population are likely to be healthy and in paid work from the age of 60 . The fitness of the worker could be assessed by three measures - life expectancy, healthy life expectancy, and HDI. As far as life expectancy healthy life expectancy and HDI are considered Sri Lanka stands at far ahead of other South Asian countries.

The healthy working life expectancy focuses on working life after age 60, which is when health problems can make it difficult for people to continue working or find an employment that 


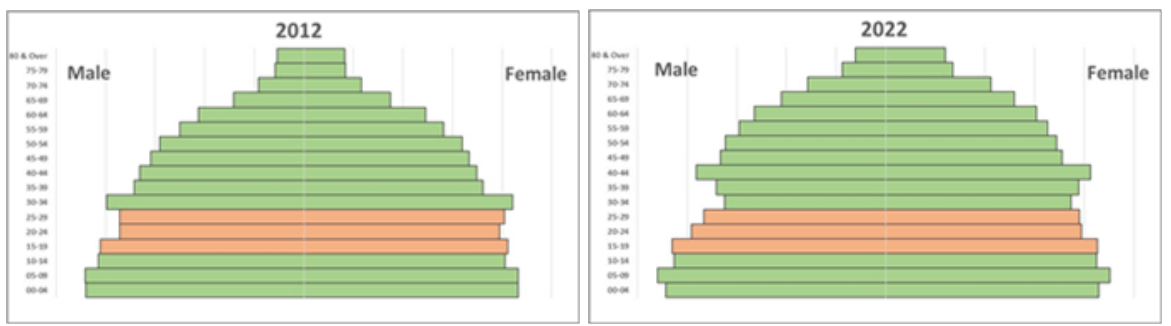

Notes: De Silva \& De Silva, 2015 [6]

Figure 1 Age and sex structure of 2012 and 2022

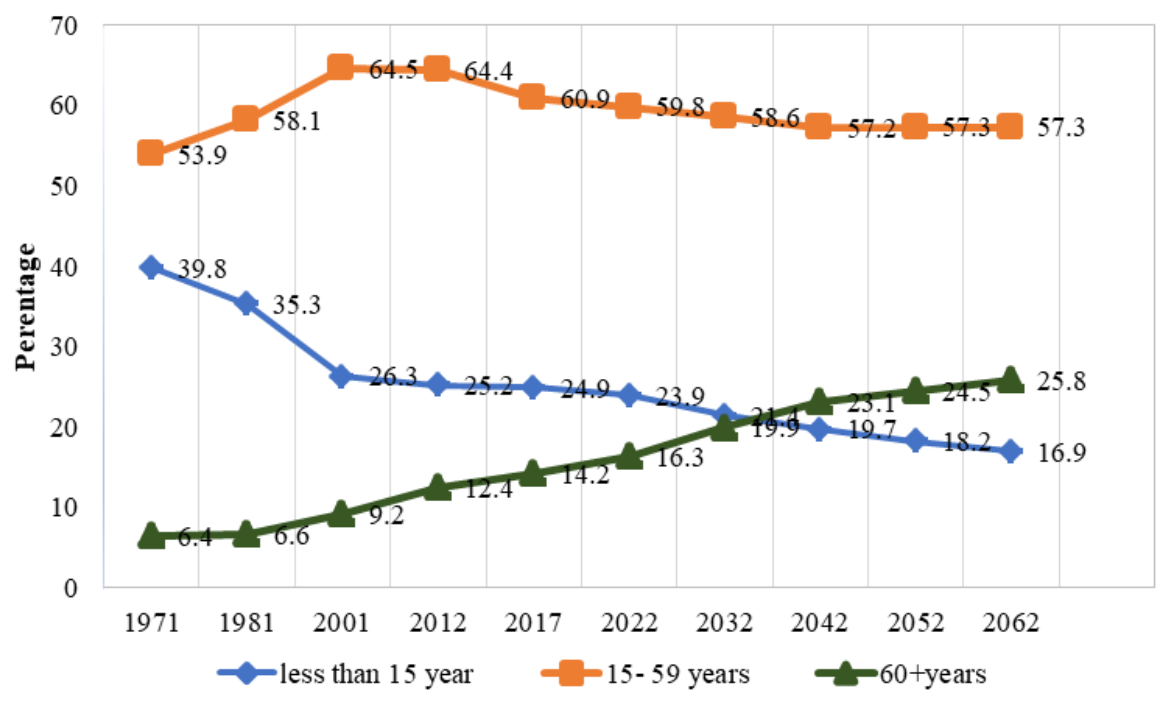

Source: De Silva, \& De Silva, (2015) [6], Population and housing projections 2012-2062.

Figure 2 Proportion of population by broad age groups, 1971-2062

fits their needs. However, during the recent past, a number of countries have changed retirement ages. New Zealand has progressively increased the standard retirement age from 60 to 65 . Japan and Korea (where the retirement age for the state pension is 65 and 60, respectively) have increased the retirement age for flat-rate benefits from 60 to 65 and in Japan the age for the income-related pension will also increase at a later date.

\section{Changes in Labour force}

Ageing is expected to affect both the supply side and the demand side of the economy. The impact of ageing on the supply side can be evaluated in terms of its impact on the determinants of growth the labour supply, capital and productivity performance. Ageing is believed to be an affecting both the supply side and the demand side of the economy. According to the Gaminiratne (2004) [8] supply side concerned all three determinant of growth, labour supply, productivity and capital, will have significantly effects arising due to population ageing. According to the De Silva \& De Silva (2015) [6] population projection clearly evident that one. Figure 2 shows that the proportion of working age population may increase till later par of 2012. In year 2012, this figure is 64.4 percent of the total population. There after population group 15-59 may be decline. Ageing is believed to be changing the age composition of the labour force.

\section{Managing pension programs in 21st century}

The rapid population change is affecting the Sri Lankan economy in several ways. Commitment and capabilities of working age population and the work force directly affects the country's output and income generation. The shortage of workers has led to higher prices for labor, which in turn has led to an increase in wages. Also, as the elderly population grows, so does the cost of their needs. On the other hand, as projected, Sri Lankan's dependency is likely to grow in time to come. Therefore, number of pensioners will be increasing in coming years. This may 
be developed various kind of effects on country's economy. As far as the economic impacts of ageing Sri Lankan's socio economic context is concerned the increasing old dependency will be one kind of prominent burden in the country.

On the other hand, increasing older generation will have negative effects on the country's economy. Considering the macro-economic context, saving will decline paving way to reduction in investment and finally a decline in macro-economic growth in Sri Lanka. with the reduction of labour force in near future, the tax base of the government will shrink in a situation. Hence many budgetary allocations are needed to look after need of the senior citizen. It will make more pressure not only the government but also on the work force in the country. On the other hand, in Sri Lanka, pension payment is paid through recurrent expenditure of the government. Table 3 reveals that the share of GDP for pension and recurrent of expenditure.

Table 3 Share of GDP for pension and recurrent of expenditure

\begin{tabular}{lcc}
\hline Year & Share of GDP (\%) & Share of Recurrent Expenditure (\%) \\
\hline 2015 & 1.4 & 10 \\
2016 & 1.4 & 10 \\
2017 & 1.3 & 9 \\
2018 & 1.4 & 9 \\
2019 & 1.5 & 10 \\
\hline \multicolumn{2}{l}{ Source: Cantal Bank, 2019 [9]. }
\end{tabular}

Table 4 shows that the number of retirees and annual expenditure on pensions. In 2019 total number of pensioners was 639,984 while for 2018 it was 621,905. However, in 2019 total amount paid as pension payments amounted to Rs.203 million rupees, while in year 2018 that amount was 182 million rupees (Department of Pension, 2020 [5]).

Table 4 Number of government retirees and annual expenditure on pensions

\begin{tabular}{ccc}
\hline Year & Number of total pensioners & Annual cost (Rs.) Million \\
\hline 2015 & 560,462 & 147 \\
2016 & 579,508 & 165 \\
2017 & 600,867 & 174 \\
2018 & 621,905 & 182 \\
2019 & 639,984 & 203 \\
\hline
\end{tabular}

Source: Department of Pension, 2020 [5].

Further data reveal that large number of new pensioners will be added to the existing number of pensioners timely manner. Table 5 shows that the number of new retires by year 2015-2019. In addition, Table 4 reveals that the distribution of share of GDP and recurrent of expenditure. In this manner the increase in the life expectancy lengthens the period of pensioners receive pension payments not only for that but also considerable number of new pensioners are being added on yearly, creating additional pressure on the annual budget of the country.

Table 5 Number of government new pensioners 2015-2019

\begin{tabular}{lccc}
\hline Year & Forces & Civil & Total \\
\hline 2015 & 6,821 & 14,212 & 21,033 \\
2016 & 5,188 & 16,523 & 21,711 \\
2017 & 5,873 & 17,181 & 23,054 \\
2018 & 9,829 & 16,797 & 26,626 \\
2019 & 9,215 & 15,924 & 25,139 \\
\hline Source: Department of Pension, 2020 [5]
\end{tabular}

Considering the contributory pension schemes in Sri Lanka it also getting into the same problematic situation. The Farmers and Fisherman's pension funds have totally collapsed. These two schemes create an additional pressure on the annual budget of the government to provide monthly pension for tagged pensioners. According to the World Bank (2008) [1] the ageing will create a massive number of poor for the poorest people who are depending on their children or on social assistance provided by the government.

Data in Figure 3 reveal that increasing the mandatory retirement age of the country may provide an additional labour supply to the shrinking workforce of Sri Lanka. Therefore, this will be a practical solution to overcome the challenges of the shrinking labour force of the country. According to Amarabandu (2004) [10], there will be positive effect with the increase in the mandatory retirement age of the country since the contributory period on pension schemes 


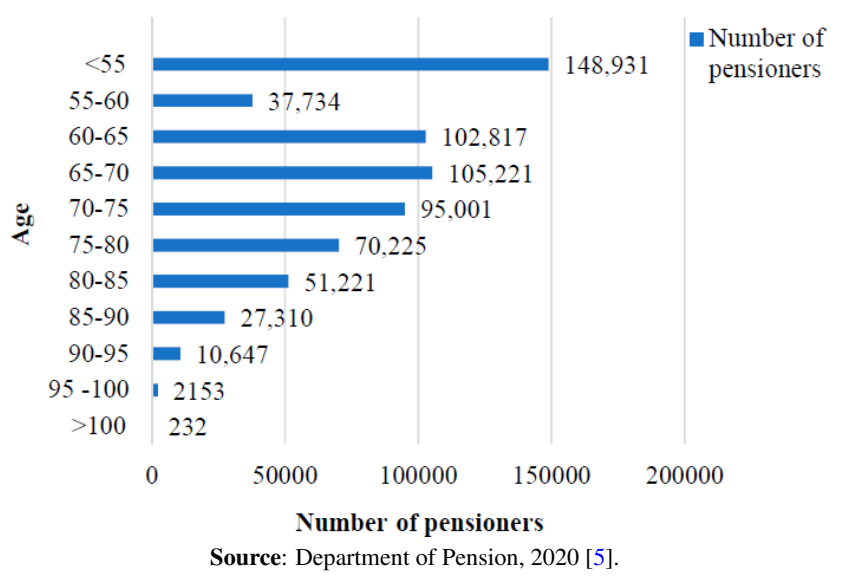

Figure 3 Number of government pensioners by age, 2019

increase and the number of years pensioners are provided to the beneficiaries may decline. Therefore, people who are capable of working few more years after the age 60 may continue to work a couple of more years. However, at the same time the State should be in a position to generate suitable employment opportunities locally to the youth in coming years and also promote foreign employment through enhancing their skills and capacities. Failing that Sri Lanka may face with youth unrest as that has been observed in a number of occasions in the recent past.

\section{Conclusion}

According to the achievements in life expectancy, healthy life expectancy, and HDI Sri Lanka demonstrate the fact that Sri Lankans are capable of working few more productive years before retirement. Compared with other south Asian countries, Sri Lankans exhibited healthy life. Countries with similar health status that of Sri Lanka in the South Asian region seem to be working for extending retirement age. Sri Lankans demonstrate a premature retirement of their working life. Sri Lanka shows the fastest aging country in South Asia region will face a decline in its laboure force due to rapid ageing process. However, providing financial and other welfare requirements to the retired who are still capable of working may create pressure not only the government but also on the work force. On the above backdrop, it seems that increasing the mandatary retirement age of the country is long overdue. Therefore, present retirement age could be placed beyond 60 years pacing it 63 for all state and private employees is a better view.

\section{References}

[1] World Bank. Sri Lanka: Addressing the need of an ageing population. Washington, 2008.

[2] Parliament of Democratic Socialist Republic of Sri Lanka Ordinance No.11 of 1910: Public and judicial officers (retirement) ordinance, Government of Sri Lanka. Colombo, 1910.

[3] Parliament of Democratic Socialist Republic of Sri Lanka. judicature Act, Government of Sri Lanka. Colombo, 1978.

[4] United Nations. ESCAP Population Data sheet: Emerging Social Issues Division United Nations Economic and Social Commission for Asia and Pacific. Bangkok, 2018.

[5] Department of Pension. Wishrama, annual report 2020. Colombo, 2020.

[6] De Silva WI and de Silva R. Sri Lanka: 25 million people and implications - population and housing projections, 2012-2062, United Nations Population Fund. Colombo, 2015.

[7] De Silva I. Construction and Analysis of National and District Life tables of Sri Lanka200 - 2002, Ministry of Health care and Nutrition. Colombo, 2008.

[8] Gaminiratne N. Population Ageing, Elderly Welfare and Extending Retirement Cover: The Case Study of Sri Lanka (ESAU Working Paper 3). Overseas Development Institute, London, 2004.

[9] Central Bank of Sri Lanka. Annual Report 2019, Central Banka of Sri Lanka: Colombo, 2019.

[10] Amarabandu WP. Elderly population and Social Security in Sri Lanka. Ageing population in Sri Lanka Issues and future prospects, United Nations Population Fund. Colombo, 2004. 